\title{
The Role of Phonology and Morphology in the Development of Basic Reading Skills of Dyslexic and Normal Native Arabic Readers
}

\author{
Salim Abu-Rabia, Nariman Abu-Rahmoun \\ Faculty of Education, University of Haifa, Haifa, Israel \\ Email: Salimar@edu.haifa.ac.il \\ Received August $6^{\text {th }}, 2012$; revised September 10 $0^{\text {th }}, 2012$; accepted September 21 $1^{\text {st }}, 2012$
}

\begin{abstract}
This study is an investigation of the role of some basic reading skills of dyslexic $(n=27)$ and normal readers of Arabic: A reading-age-matched group $(n=29)$ and a chronological age-matched group $(n=31)$. The children were tested on reading and cognitive measures, all of which had vowelized and unvowelized versions: phonological, orthographic, reading, spelling, syntax, and working memory skills. The results of the MANOVA revealed significant differences between the dyslexic readers and the two control groups on most measures. Moreover, main effects of vowels and roots were found. In other words, subjects were much better at the vowelized than the unvowelized tests and used morphology to assist their reading accuracy. However, the Stepwise Regression analysis revealed that syntax, reading measures (isolated words, real roots and false roots), morphology and spelling were the most powerful predictors of reading accuracy among dyslexic and normal readers.
\end{abstract}

Keywords: Dyslexia in Arabic; Morphology; Phonology (Short Vowels); Dyslexia in Semitic Orthographies

\section{Introduction}

Reading is a complex process that includes the development of phonological, orthographic, syntactic and working memory skills. Normal readers usually develop these skills around 2 - 9 years of age. While the phonological skills ease the process of recoding and identifying words, the syntactic skills enable the reader to benefit from the sentence context through his/her textual reading process (Abu-Rabia, 1995, 2002; Muter, 1998; Siegel \& Ryan, 1984, 1988). Readers with reading disabilities show difficulties in their phonological decoding process (Bradley \& Bryant, 1983; Siegel \& Ryan, 1984; Shankweiler et al., 1995) and in their syntactic abilities (Ben-Dror, Bentin, \& Frost, 1995; Carlisle, 1995; Henry, 1993; Leong, 1999; Siegel \& Ryan, 1988; Tyler \& Nagy, 1990).

Researchers define dyslexia in different ways (Abu-Rabia, 2002; Ben-Dror, Bentin, \& Frost, 1995; Stanovich, 1988). Some argue (Bentin et al., 1995) that dyslexia is related to a deficit in a number of skills, phonological and syntactic awareness. AbuRabia (2002) claims that dyslexia is a delay in all language skills (Abu-Rabia \& Taha, 2004) and that such a delay causes a gap between the chronological age of the reader and his/her reading age. This gap could reach two or more years. In this case, dyslexic readers in grade 4 would read at the level of grade 2 (Fowler \& Liberman, 1995; Genard et al., 1998; Sprenger-Charolles et al., 2000; Stanovich, 1991).

Most research studies of dyslexia have focused on the development of the phonological skills (Ben-Dror, Bentin, \& Frost, 1995; Felton, 1998; Fowler \& Liberman, 1995; Webster, 1994), while the development of the morphological skills have attracted less attention (Ben-Dror et al., 1995; Carlisle, 1995; Fowler \& Liberman, 1995). In addition, most of the studies have tested phonology in the Latin orthography, which limits generalization of their results. Thus, testing different orthographies is essential to the development of a cross-cultural comprehensive theory. So far only a few studies have tested the morphology of Arabic (Abu-Rabia et al, 2003; Abu-Rabia \& Awwad, 2004; Beland \& Mimouni, 2001). The purpose of this study is to test the role of morphology in reading along with a cluster of basic reading, writing and cognitive variables among normal and dyslexic native Arabic speakers. In order to understand the results of this study, it is essential to know the nature of Arabic orthography. First, the nature of Arabic will be presented and then the review of the literature.

\section{Arabic Orthography}

Arabic is a language written in an alphabetic system of 28 letters, all consonants except three, the long vowels. Most Arabic letters have more than one written form, depending on the letter's place in a word: beginning, middle, or end. For example, the letter $\dot{\tau^{-}}|\chi|-$ (this is the separated mode of the letter) is written at the beginning of the word $(\dot{)})$, in the middle of the word $(\dot{)})$ and at the end of the word ( $\dot{z})$. The essential shape of the letter, however, is maintained in all cases (Abd El-Minem, 1987; Madkor, 1987). In addition, the letters are divided into categories according to basic letter shapes, and the difference between them is the number of dots on, in or under the letter

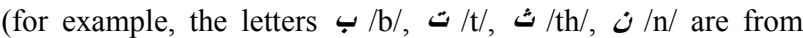
the same category). Dots appear within 15 letters, 10 of which have one dot, three have two dots, and two have three dots. These dots are part of the consonant letters. In addition to the dots, there are diacritical marks that contribute phonology to the

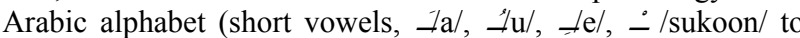


indicate silent sounds, $\because$ shadda/- to indicate stressed syllables) (Abu-Rabia, 2001, 2002, 2007; Isa, 2000; Madkor, 1987). Arabic words are a combination of consonants and vowels. Skilled and adult readers are expected to read texts without short vowels, but this demands heavy reliance on context and other resources. Beginners and poor readers read texts with short vowels. Vowelized Arabic is considered to be shallow orthography, and unvowelized Arabic is considered to be deep orthography. Reading accuracy in Arabic requires vowelizing word endings according to their grammatical function in the sentence, which is an advanced linguistic ability (phonological and syntactical abilities) (Abu-Rabia, 2001, 2002, 2007). On the other hand, silent reading comprehension is less strict, because the reader can rely on orthography, morphology, and other resources (Abu-Rabia, 2001, 2002, 2007).

\section{Arabic Morphology}

Arabic morphology is built of two types of structures: derivational and inflectional.

Derivational morphology. All words in Arabic are based on phonological patterns built on roots that are consonantal patterns. For example, the word /كاتب/ kateb/writer/ is constructed from the root /k-t-b/ which semantically, has to do with writing and the pattern (-a-e-) that indicates the person who is performing the action. Roots are triliteral (like k-t-b) or quadrilateral (/d-h-r-j/ to roll/), that is, with three or four consonants. The phonological pattern is constructed of: a) short vowels built onto roots; b) patterns that include vowel letters, which are inserted between the root consonants; c) the phonological process does not break the orthographic order of the consonantal root (example, the verb كتَب /inkataba/ has been written-the passive form of كَتَب / $/ \mathrm{kataba} /$ wrote/). With inserted vowels the phonological pattern of the infixes breaks the orthographic order of the consonantal root (example, the noun كَاتِ / $/ \mathrm{kateb} /$ writer/). Further, additional patterns with vowel letters that may added as prefixes or suffixes - in this case (example, the noun مَكْتُوب=/maktoub/written-letter). The root conveys the initial lexical access and the combination of roots and phonological patterns conveys specific semantics (Frost, Forster, \& Deutsch, 1997).

The derivational morphology has two types of word patterns: verbal word patterns and nominal word patterns. There are 15 frequent verbal word patterns in Arabic. Each verbal word pattern determines the inflectional pattern of the word (Abd ElMinem, 1987; Isa, 2000; Madkor, 1987). The verb pattern conveys basic semantics via verb roots, and it can change the meaning of a new word based on that root; different verb patterns built on the same root may convey different semantics (Abd El-Minem, 1987; Isa, 2000; Madkor, 1987). There are nine nominal word patterns. There is semantic consistency in all these different nominal word patterns (Bentin \& Frost, 1995), some of which are more common than others. The derivations of nouns are constructed in two ways, one by addition of nominal patterns to the base roots and one by changing the past tense to the present tense by applying a phonological pattern to the latter (Abd El-Minem, 1987; Isa, 2000; Madkor, 1987).

Inflectional morphology. In contrast to the derivational process, in which the basic constituents are roots and word patterns, the inflectional morphological system in Arabic is constructed by attaching prefixes and suffixes to real words. The system of inflectional morphology of verbs is systematic and considers person, number, gender and time. In the past tense, inflectional morphology shows person, number, and gender through the addition of suffixes to the basic verb pattern (third person masculine singular. Example: the word كَّب /kataba/ he wrote

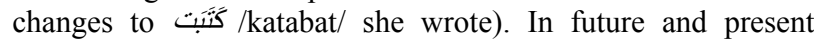
tenses of verbs, the inflectional morphology is also according to person, number, and gender, indicated by prefixes and sometimes suffixes (for example: بَكُتُبُ /yaktobo/ he writes/ changes into تَكَتُبُ /taktobo/ she writes/). The imperative mood is formed for person, number, and gender by the addition of prefixes and suffixes (for example: أَكْتُبْ /oktob/ write (masculine) change into أكتُبِ /oktobey/ write (feminine ending) (Abd El-Minem, 1987; Isa, 2000; Madkor, 1987). The inflectional morphological system of nouns considers gender (masculine/ feminine), number (singular/plural), masculine and feminine and pairs masculine/feminine.

Table 1 shows how the root $/ \mathrm{k}-\mathrm{t}-\mathrm{b} /$ changes using the noun pattern "writer" for gender and number.

Most verbs and the majority of nouns are constructed out of three consonant roots, occasionally two or four. Roots are built in phonological patterns to create specific words. These patterns may be a series of consonants or a series of vowels and consonants. As for roots and morphemic word patterns, most words in Arabic are constructed of two morphemes: the combination of a root and a word pattern creates a certain word. Different morphemes convey different types of information: the root conveys semantic information then the phonological pattern which determines the core meaning of the word (AbuRabia, 2002, 2001), whereas the word patterns usually convey information on word class.

In sum, the combination of morphological units in Arabic is not linear. It relies on intertwining between two independent morphemes (the root and the word pattern). The order of root letters is dependent upon the word pattern and its way of intertwining with the root. The word pattern can be built of prefixes, suffixes and infixes whose intertwining with the root can break the order of the root letters (Feldman \& Bentin, 1994).

\section{Review of the Literature}

Phonological decoding. Phonological decoding ability is essential in the process of reading acquisition (Abu-Rabia, 1995, 2001; Jorm \& Share, 1983; Perfetti, 1985; Share, 1995). It is well established in the literature that measuring pseudoword reading is the benchmark test of children's phonological decoding skill (Abu-Rabia, 1995; Vellutino \& Scanlon, 1987). Many studies have been conducted using pseudowords as their phonological decoding measure among normal readers and reading-disabled (RD) children (Bruck, 1988, 1990; Castles \& Coltheart, 1993; Ehri \& Wilce, 1983; Jorm \& Share, 1983; Share, 1985; Perfetti, 1985; Siegel, 1989; Siegel \& Ryan, 1988; Stanovich \& Siegel, 1994). The difficulty these RD children have in reading pseudowords seems to be the result of deficiencies in their basic phonological processing.

Table 1.

Root /k-t-b/ changes, gender, and number.

\begin{tabular}{cccc}
\hline Gender/Number & Singular & Pairs & Plural \\
\hline Masculine & /kateb/ & /kateban/ & $/$ katebon/ \\
Feminine & $/$ kateba/ & /katebatan/ & /Katebat/ \\
\hline
\end{tabular}


Orthographic processing. The orthographic component makes an important contribution to reading over and above phonological decoding (Cunningham \& Stanovich, 1990; Stanovich \& West, 1989). In spite of the different orthographic testing measures, specific orthographic knowledge and orthographic combination however, the results for disabled readers are similar in many studies. On orthographic measures, RD children performed as well as or even better than their normal counterparts matched by reading-level age (Abu-Rabia, 1995; Siegel, 1986). Their performance was poorer, however than that of their chronological age counterparts. Thus, RD children are relatively better at visual-orthographic processing than phonological processing.

Syntax. Studies measuring syntactic ability in normal and RD students have all resulted in superior performance by normal readers (Abu-Rabia, 1995; Bentin, Deutsch, \& Liberman, 1990; Deutsch \& Bentin, 1996; Fowler, 1988; Menyuk, 1981; Siegel \& Ryan, 1988; Stanovich \& Siegel, 1994; Vellutino, 1979; Vogel, 1974; Willows \& Ryan, 1981), although the interpretation of these findings has been controversial (Bryant, Maclean, \& Bradley, 1990).

Phonological Awareness. Phonological awareness is the knowledge that spoken words are composed of phonemes and syllables, operationalized as the ability to analyze words into phonemes and syllables (Hakes, 1982; Mattingly, 1984). Children first focus on the content and use of words, and only later notice the phonological structure of the language; next they learn that utterances are composed of words that may even rhyme with one another. This ability is realized when children notice the structure of the spoken language and acquire some control over phoneme manipulation (Liberman, Shankweiler, Fischer, \& Carter, 1974; Menyuk, Chesnick, Liebergott, Korngold, D'Agostino, \& Belanger, 1991).

Morphology. Morphology describes words' morphemes, which are the basic semantic units of the language (Hockett, 1958). $\mathrm{RD}$ individuals have difficulty dealing with morphology (Leong, 1989). Their reading process is dependent on their ability to apply morphological rules of the language (Abu-Rabia \& Taha, 2004; Vogel, 1975, 1983).

Ben-Dror and her colleagues tested morphology, phonology, and semantics of Hebrew in 60 students who were divided into three sub-groups: a group of RD children in grade 5, a control group of normal readers matched by chronological age, and a younger control group matched by reading level. The RD children performed poorly compared to the chronological-age control group and were slower than the younger control group. The most significant differences were found in the morphological tasks (Abu-Rabia, Share, \& Mansour, 2003; Ben-Dror et al., 1995).

Working memory. This ability involves executive control of processing cognitive ability, which helps to control all operations performed in tasks such as reading (Baddeley \& Hitch, 1974). Many studies investigating working memory among RD children have found impaired working memory performance as compared with normal readers (Abu-Rabia \& Siegel, 2002, 2003; Abu-Rabia, 1995; Brady, Mann, \& Schmidt, 1987; Cermac, 1983; Daneman, Carpenter, \& Just, 1982; Holligan \& Johnston, 1988; Jorm \& Share, 1983).

Visual-orthographic processing. There is some evidence, although not consistently replicated, of deficiencies in basic visual processing in RD children (Crammond, 1992; Fletcher, 1985; Lovegrove, 1993; Meyler, 1993; Meyler \& Breznitz,
1998). In a longitudinal study conducted in Hebrew, Meyler and Breznitz (1998) tested the development of visual and verbal memory in children followed from kindergarten to grade 2 . They found positive significant predictive correlations between both visual and verbal ability and reading. An important difference between English and Hebrew is worth noting: pointed Hebrew writing may require unique visuo-spatial processing due to the visual complexity of vowel diacritics (Share \& Levin, 1999). We expect a similar behavior in reading vowelized Arabic orthography (Abu-Rabia \& Taha, 2006; Ibrahim, Eviatar, \& Aharon-Peretz, 2002).

\section{Defining Reading Disability}

Reading disability is conventionally defined as "difficulty in acquiring reading skills in spite of being taught by conventional methods, good intellectual abilities and acceptable societal occasions" (Critchley, 1970). This definition implicitly assumes that IQ represents learning potential (Stanovich, 1991). Nowadays, developmental and educational psychologists oppose the view that the IQ test measures intellectual potential (Anastasi, 1988; Cronbach, 1984; Siegel, 1999; Stanovich, 1991; Thorndike, 1986) and should only be viewed as a raw measure of present cognitive functioning (Detterman, 1982; Humphreys, 1979). The decision to use a specific reading disability group in the present study was not based on the conservative rationale of the importance of IQ, but on the rationale that this specific reading disability group was a relatively pure one, and this would enable us to study methodologically the specific characteristics of poor reading not caused by factors associated with general cognitive delay.

\section{The Present Study}

The characteristics of Arabic RD children have not been largely studied. The present study compared three different groups: reading-disabled Arab children, normal readers matched by chronological age, and normal readers matched by reading level. On the basis of our brief literature review we expected to find many similarities in the reading-related deficits in English orthography and the Arabic orthography (principally phonological and orthographic), as both are alphabetical scripts. Some inconsistencies were also expected, however, due to the nature of Arabic orthography. We expected that RD children would perform significantly worse in word recognition and many basic cognitive processes than chronological-age-matched normal readers and younger reading-level-matched normal readers. In the orthographic processing task, however, RD children were expected to perform the same as or better than younger normal readers. In contrast, on word recognition processes (phonological decoding) and cognitive processing, reading-disabled children were expected to perform significantly worse than younger normal readers. Because the Arabic writing system is visually complex (connection of letters and short vowelization), significant relationships between visual processing and reading in the Arabic language were predicted. Namely, $\mathrm{RD}$ children were expected to show more difficulties in those tasks than normal readers matched by both chronological age and reading level.

\section{Method}

Sampling. The initial sample of the study was 221 students, 
116 from grade 8 and 105 from grade 6. Among the eighth graders, 27 students were screened as dyslexic readers and 31 students as their chronological age-matched group. Among the sixth graders, 29 students were screened as the young readinglevel matched group.

The dyslexic group. The dyslexic children were diagnosed in their school. All the students $(n=116)$ were tested and 27 of them were diagnosed as dyslexic readers; 10 females and 17 males. Their mean chronological age in years was 13.91 (SD = 0.43 ). The screened dyslexic group was comparable to grade 6 in their reading age based on their reading performance on a written test and a list of isolated words (Abu-Rabia, 2005).

The additional criterion for the screened participants was their performance on general ability tests (see Table 1). The dyslexic group showed adequate performance on the Raven, Raven \& Court (1993) and the visual perception test (Beery, 1997).

\section{The Control Groups}

Reading-level-matched. From the initial sample of 105 students from grade 6 , a group of 29 was selected that matched the dyslexic readers from grade $8(n=29)$ in their reading performance. There were 17 females and 12 males, with a mean age in years of $12.08(\mathrm{SD}=0.16)$. This young group showed reading ability similarity to the dyslexic readers but differed on the general ability tests (Raven, Raven, \& Court, 1993; Beery, 1997).

Age-matched. From the initial sample of 116 students from grade 8, 31 students, 15 females and 16 males, were screened based on their performance on the general ability tests. Their mean age in years $13.72(\mathrm{SD}=0.40)$. The screened participants were similar in their general ability performance to the dyslexic readers (see Table 2).

In order to test the performance differences between the groups, t-test procedures were used. The results showed that there were no significant differences between the dyslexic group and the chronological age-matched group on the general ability tests; however, they differed significantly on the reading measures $(p<0.05)$. However, the differences between the dyslexic group and the reading-level-matched group on the same tests, general ability and reading, revealed significant differences $(p<0.05)$. The results validate the suitability of the three groups to our study.

\section{Testing Tool}

The Raven-R (Raven, Raven, \& Court, 1993) tests the nonverbal thinking level: the ability to create comparisons, analogies, inductions and deductions.

Phonological awareness $(\alpha=0.77)$. Two lists of pseudowords

Table 2.

Means and standard deviations of the three groups on reading and general ability tests.

\begin{tabular}{cccc}
\hline Tests & $\begin{array}{c}\text { Dyslexic } \\
(\mathbf{n}=\mathbf{2 7})\end{array}$ & $\begin{array}{c}\text { Reading level } \\
(\mathbf{n}=\mathbf{2 9})\end{array}$ & $\begin{array}{c}\text { Age-matched } \\
(\mathbf{n}=\mathbf{3 1})\end{array}$ \\
\hline Raven & $37.44(8.97)$ & $30.52(7.39)$ & $40.19(6.84)$ \\
Visual perception & $23.92(2.46)$ & $22.03(1.96)$ & $24.74(1.39)$ \\
Reading & $54.88(9.66)$ & $53.09(5.23)$ & $84.86(3.43)$ \\
\hline
\end{tabular}

were presented. Each list included 26 pairs of pseudowords and only one pseudoword sounded like a real word. One list was presented with full vowelization and the other without (example:

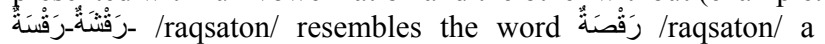
dance/, the other pseudoword/raqshaton/ is the wrong answer. The letters $ص$, might be homophones and resemble in their representation the sound $/ \mathrm{s} /$ ).

Pseudoword reading. This test was built for the purposes of this study. Four lists of pseudowords were constructed, 30 items in each list. The first two lists included pseudowords with real roots, one fully vowelized $(\alpha=0.96)$ and one without vowelization $(\alpha=0.93)$. The other two lists included false roots, one list with full vowelization $(\alpha=0.95)$ (for example, /estafrabat/) and the other without $(\alpha=0.93)$ (for example, إطهاب /et-hab/).

Isolated words. Two lists of words were constructed for this study, with 40 words in each; one list was with full vowelization $(\alpha=0.96$, for example: رَمْز /ramzan/ symbol) and the other was without ( $\alpha=0.96$, for example: يستكثنفون

/yastakshifon/-discovering). Both lists were constructed on the basis of gradually increasing difficulty.

Spelling. A list of 40 words of gradually increasing difficulty was constructed $(\alpha=0.82)$. The words were selected from the basal reader of grade 8 .

Words that do not fit the context. Two lists of sentences were constructed that included words that did not fit the context (for example: إسنتَعْلَ الْعامِلُ القُطْنَ في صَنْع الإطارات - the worker used cotton in manufacturing tires). One list was presented with full vowelization $(\alpha=0.97)$ and the other one without vowelization $(\alpha=0.92)$. Each list included 30 sentences.

Working memory. This test was based on the idea of Siegel and Ryan (1989). An Arabic version was adapted. The participants were presented with sentences orally with the final word missing; they had to supply it and repeat all the missing words from the set. There were three trials in each set size $(2,3,4$ and $5)$.

\begin{tabular}{ll}
\hline. & we go fishing in the \\
\hline & we go to the bookstore to buy \\
\hline
\end{tabular}

Morphological identification. Four lists of words were presented. The participants had to identify the root of each word. The first two lists included 36 words each; the first was fully vowelized $(\alpha=0.83)$ and the other was not $(\alpha=0.84$, for ex-

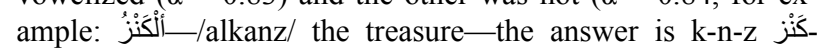
there are no letters interrupting the root, only short vowels). The other two lists included 40 words each, and words were based on disrupted roots: one list was presented fully vowelized ( $\alpha=0.92)$ and the other without ( $\alpha=0.90$, for example: شَاهَ /shaahada/ witnessed/ the answer is /sh-h-d/ the letter / $/ /$ aa/ interrupted the root).

Morphological production. A list of 40 roots was presented where the participants had to derive words from each root in the list $(\alpha=0.88)$, for example: عد /a'dad/number/ the answers could be: عَعداد /aa'ad/ numbers/, تعدَّاد /a'deed/a lot of /tea'dad/ counting/, مِعَّ /mea'dd/ counting machine/etc.).

Syntax. Two lists of sentences were presented; one with full vowelization $(\alpha=0.75)$ and one without $(\alpha=0.83)$. Each list consisted of 30 sentences, half of which had syntactic errors. The participants had to judge whether the sentence was syntac-

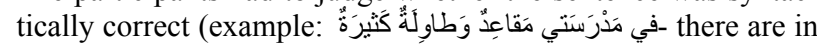


my school a chairs and a table. The right sentence should be:

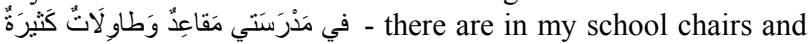
tables.

Orthographic awareness. Two lists of homophonic words were constructed. Each list consisted of 22 pairs of correct and misspelled homophonic words. One list was fully vowelized $(\alpha$ $=0.86)$ and the other was not $(\alpha=0.72)$. The participants had to choose the word that was spelled correctly (example: بكا_بكى - cried - the underlined word in the right one).

Reading comprehension. Two tests were chosen from the students' basal reader for grade 8 . Both texts were equal in length, 16 lines each. One text was with full vowelization $(\alpha=$ $0.71)$ and the other was without $(\alpha=0.75)$. Both texts were informative; one text was about computers and the other was about cars.

\section{Procedure}

The testing procedures were conducted at the school in a quiet room dedicated specifically for the purpose of this study. Testing took place during the regular school days of the week Tests were conducted on a one-on-one basis, except for spelling, morphological, orthographic, syntax and reading comprehension tests which were conducted in groups. The order of the tests was counterbalanced across participants. All the reading aloud measures (the one-on-one tests) were tape recorded.

\section{Results}

The data was analyzed with the SPSS statistical package. Multiple analysis of variance (MANOVA) was used to test the differences between and within groups on all measures. In addition, to locate the source of variance, the Tukey post hoc test was used. Further, stepwise regression analysis was used to locate the powerful predictors of word reading among the three groups of the study.

Table 3 presents the means and standard deviations of the three groups. A MANOVA revealed a main effect for voweli

Table 3.

Descriptive statistics of all groups on all measures.

\begin{tabular}{|c|c|c|c|c|}
\hline Variables & Dyslexics & Reading Level & Chronological Age & $\mathbf{F}$ \\
\hline Vowelized phonology & $\begin{array}{c}17.63 \\
(1.80)\end{array}$ & $\begin{array}{l}22.07 \\
(2.20)\end{array}$ & $\begin{array}{l}23.58 \\
(1.57)\end{array}$ & $77.46^{* * *}$ \\
\hline Unvowelized phonology & $\begin{array}{c}14.96 \\
(2.01)\end{array}$ & $\begin{array}{l}20.38 \\
(3.09)\end{array}$ & $\begin{array}{l}21.74 \\
(1.67)\end{array}$ & $66.85^{* * *}$ \\
\hline Vowelized orthography & $\begin{array}{l}19.07 \\
(2.53)\end{array}$ & $\begin{array}{l}19.93 \\
(1.62)\end{array}$ & $\begin{array}{l}20.03 \\
(1.60)\end{array}$ & 2.06 \\
\hline Unvowelized orthography & $\begin{array}{l}16.48 \\
(2.76)\end{array}$ & $\begin{array}{l}18.38 \\
(2.31)\end{array}$ & $\begin{array}{c}18.19 \\
(1.76)\end{array}$ & $5.82^{* *}$ \\
\hline Vowelized syntax & $\begin{array}{c}16.96 \\
(4.90)\end{array}$ & $\begin{array}{l}16.45 \\
(4.38)\end{array}$ & $\begin{array}{l}24.84 \\
(2.72)\end{array}$ & $40.25^{* * *}$ \\
\hline Unvowelized syntax & $\begin{array}{l}14.81 \\
(4.90)\end{array}$ & $\begin{array}{l}15.48 \\
(4.49)\end{array}$ & $\begin{array}{l}23.29 \\
(3.40)\end{array}$ & $36.29^{* * *}$ \\
\hline Vowelized morphology with undisrupted root & $\begin{array}{l}31.15 \\
(3.60)\end{array}$ & $\begin{array}{l}30.21 \\
(6.40)\end{array}$ & $\begin{array}{l}35.81 \\
(3.16)\end{array}$ & $12.74^{* * *}$ \\
\hline Unvowelized morphology with disrupted root & $\begin{array}{l}30.15 \\
(3.45)\end{array}$ & $\begin{array}{l}28.00 \\
(6.31)\end{array}$ & $\begin{array}{l}33.61 \\
(3.43)\end{array}$ & $11.40^{* * *}$ \\
\hline Vowelized morphology with disrupted root & $\begin{array}{l}31.52 \\
(7.42)\end{array}$ & $\begin{array}{l}31.41 \\
(8.01)\end{array}$ & $\begin{array}{l}36.00 \\
(4.09)\end{array}$ & $4.62^{*}$ \\
\hline Unvowelized morphology with disrupted root & $\begin{array}{l}31.52 \\
(6.22)\end{array}$ & $\begin{array}{l}29.00 \\
(7.72)\end{array}$ & $\begin{array}{l}35.45 \\
(4.47)\end{array}$ & $8.53^{* *}$ \\
\hline Vowelized reading comprehension & $\begin{array}{c}6.44 \\
(1.48)\end{array}$ & $\begin{array}{c}7.66 \\
(1.40)\end{array}$ & $\begin{array}{c}9.48 \\
(0.77)\end{array}$ & $44.50^{* * *}$ \\
\hline Unvowelized reading comprehension & $\begin{array}{c}5.33 \\
(2.59)\end{array}$ & $\begin{array}{c}4.83 \\
(1.85)\end{array}$ & $\begin{array}{c}8.32 \\
(1.19)\end{array}$ & $28.79^{* * *}$ \\
\hline Vowelized word reading & $\begin{array}{l}22.89 \\
(7.26)\end{array}$ & $\begin{array}{l}25.76 \\
(3.76)\end{array}$ & $\begin{array}{l}32.94 \\
(2.49)\end{array}$ & $33.94^{* * *}$ \\
\hline Vowelized pseudoword with real root & $\begin{array}{l}19.11 \\
(2.82)\end{array}$ & $\begin{array}{l}20.10 \\
(2.83)\end{array}$ & $\begin{array}{l}25.90 \\
(1.87)\end{array}$ & $62.70^{* * *}$ \\
\hline Unvowelized pseudoword with real root & $\begin{array}{l}14.07 \\
(4.75)\end{array}$ & $\begin{array}{l}16.72 \\
(3.97)\end{array}$ & $\begin{array}{l}21.45 \\
(2.59)\end{array}$ & $27.94^{* * *}$ \\
\hline Vowelized pseudoword with false root & $\begin{array}{l}17.44 \\
(4.82)\end{array}$ & $\begin{array}{l}19.38 \\
(3.24)\end{array}$ & $\begin{array}{l}24.65 \\
(2.12)\end{array}$ & $33.25^{* * *}$ \\
\hline Unvowelized pseudoword with false root & $\begin{array}{l}13.37 \\
(4.87)\end{array}$ & $\begin{array}{l}14.45 \\
(3.65)\end{array}$ & $\begin{array}{l}20.94 \\
(2.61)\end{array}$ & $35.05^{* * *}$ \\
\hline Vowelized words that do not fit the context & $\begin{array}{l}24.04 \\
(2.61)\end{array}$ & $\begin{array}{l}24.69 \\
(3.40)\end{array}$ & $\begin{array}{l}28.71 \\
(1.22)\end{array}$ & $29.32^{* * *}$ \\
\hline Unvowelized words that do not fit the context & $\begin{array}{l}21.00 \\
(2.80)\end{array}$ & $\begin{array}{l}21.24 \\
(2.91)\end{array}$ & $\begin{array}{l}26.42 \\
(2.22)\end{array}$ & $39.95^{* * *}$ \\
\hline Working memory & $\begin{array}{l}23.85 \\
(6.20)\end{array}$ & $\begin{array}{l}25.68 \\
(4.67)\end{array}$ & $\begin{array}{l}29.35 \\
(6.14)\end{array}$ & $7.047^{* *}$ \\
\hline Spelling & $\begin{array}{l}17.74 \\
(5.73)\end{array}$ & $\begin{array}{l}19.68 \\
(8.27)\end{array}$ & $\begin{array}{l}28.48 \\
(4.93)\end{array}$ & $23.63^{* * *}$ \\
\hline Unvowelized word reading & $\begin{array}{l}18.74 \\
(7.14)\end{array}$ & $\begin{array}{l}20.79 \\
(4.89)\end{array}$ & $\begin{array}{l}26.23 \\
(4.02)\end{array}$ & $14.93^{* * *}$ \\
\hline
\end{tabular}

Note: ${ }^{*} p<0.05 ;{ }^{* *} p<0.01 ;{ }^{* * *} p<0.001$. 
zation on all measures, $\mathrm{F}(1,84)=96.95, p<0.001 ; \mathrm{F}(1,84)=$ $123.88, p<0.01 ; \mathrm{F}(1,84)=25.79, p<0.001 ; \mathrm{F}(1,84)=26.12$, $p<0.01 ; \mathrm{F}(1,84)=5.92, p<0.05) ; \mathrm{F}(1,84)=51.22, p<0.001$; $\mathrm{F}(1,84)=193.60, p<0.001 ; \mathrm{F}(1,84)=292.97, p<0.001 ; \mathrm{F}(1$, $84)=224.79, p<0.001 ; \mathrm{F}(1,84)=130.81, p<0.001$, respectively to their order of presentation in Table 3. Furthermore, a group main effect was also obtained on all measures, $\mathrm{F}(2,84)=$ $8.976, p<0.001 ; \mathrm{F}(2,84)=6.56, p<0.001 ; \mathrm{F}(2,84)=13.64, p$ $<0.001 ; \mathrm{F}(2,84)=43.06, p<0.001 ; \mathrm{F}(2,84)=4.49, p<0.01$; $\mathrm{F}(2,84)=57.48, p<0.001 ; \mathrm{F}(2,84)=25.88, p<0.001 ; \mathrm{F}(2,84)$ $=43.68, p<0.001 ; \mathrm{F}(2,84)=39.10, p<0.001 ; \mathrm{F}(2,84)=$ $43.62, p<0.001$, respectively to their order of presentation in Table 3.

There was also a main effect of interaction; group $\mathrm{x}$ vowelization on the following measures: morphology with a nondisruptive root, $\mathrm{F}(5,80)=1.24, p<0.05$; morphology with a disruptive root, $\mathrm{F}(10,160)=3.20, p<0.05)$; reading comprehension $\mathrm{F}(10,160)=5.64, p<0.01$; word reading $\mathrm{F}(10,160)=$ $4.04, p<0.05$; pseudoword reading with a root, $\mathrm{F}(10,160)=$ $3.66, p<0.05$.

Table 3 reveals that there was no significant difference between the dyslexic group and the reading-level-matched group on all measures except for the unvowelized pseudoword reading (with false root), on which the young reading level-matched group performed better.

Furthermore, there was no significant difference between the dyslexic group and the young reading-level-matched group on the reading measures, except for unvowelized pseudoword reading with true roots, on which the young reading-levelmatched group performed better. Likewise, there was no significant difference between the dyslexics and the young and reading-level-matched group on the unvowelized reading comprehension measure. However, there was a significant difference on the vowelized reading comprehension test, on which the young reading-level-matched group and the chronologicalmatched-group performed better.

In order to test the effect of roots on the variance between the groups, a new MANOVA procedure was designed in which the pseudoword reading measures with real and false roots were calculated. The results revealed a significant effect for root:

$\mathrm{F}(1,84)=29.14, p<0.001$. The chronological-age-matched group obtained the highest scores on all measures and the dyslexic group obtained the lowest scores. This pattern was observed in the vowelized and unvowelized measures (see Table 3).

The illustration in Figure 1 shows the difference between the dyslexic group and the two control groups on the real root measures. There was a drop for all three groups in their performance on measures of false root, especially among the young reading-level-matched group. In addition, there was also a significant triple interaction of root $\times$ vowelization $\times$ group: $\mathrm{F}(2,84)=5.92, p<0.01$. Namely, the dyslexic group benefited from the roots and vowelization, while the young reading-level-matched group benefited from the root, only when they tackled unvowelized script (Table 3).

\section{Regression Results}

The stepwise regression procedures were conducted separately among the three groups. All the stepwise procedures used reading unvowelized isolated words as the dependent variable in all groups and the rest of the variables as independent variables.

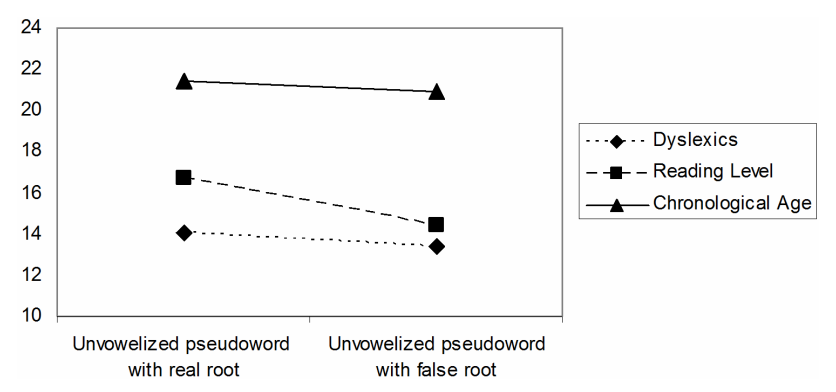

Figure 1.

Performance on pseudowords measures with real and false roots without vowelization.

Dyslexic group. Among the dyslexic group, the stepwise regression revealed that reading unvowelized pseudowords with real roots was the strongest predictor of performance when reading unvowelized isolated words: it explained $70 \%$ of the variance: $\mathrm{F}(1,26)=56.17, p<0.001$. This was followed by vowelized isolated words, which added $5 \%, \mathrm{~F}(2,26)=35.90$, $p<0.001$, that is, both predicted $75 \%$, while the rest of the variables did not show any significant prediction. Furthermore, in a similar procedure, when only the vowelized scores were entered as independent variables, reading vowelized pseudowords with real roots revealed a significant contribution, $58 \%, \mathrm{~F}(1,26)=34.90, p<0.001)$; vowelized isolated words, $13 \%, \mathrm{~F}(2,26)=29.77, p<0.001$; reading vowelized words that do not fit the context, $5 \%, \mathrm{~F}(3,20)=24.55, p<0.001$; working memory, $4 \%, \mathrm{~F}(4,26)=22.63, p<0.001$; and vowelized syntax, $5 \%, \mathrm{~F}(5,26)=24.39, p<0.001$. All these variables together explained $85 \%, \mathrm{~F}(5,26)=24.39, p<0.001$. However, when only the unvowelized measures were entered as independent variables, unvowelized pseudowords with real roots revealed a significant prediction, $69 \%, \mathrm{~F}(1,26)=56.17, p<$ 0.001 ; spelling, $4 \%, \mathrm{~F}(2,26)=34.90, p<0.001$; and working memory, $4 \%, \mathrm{~F}(3,26)=29.04, p<0.001$. All these variables together explained $79 \%, \mathrm{~F}(3,26)=29.04, p<0.001$.

Reading-level-matched group. The same stepwise procedures were used here. The vowelized reading isolated words was a significant predictor, explaining $70 \%$ of the variance, $\mathrm{F}(12,28)$ $=62.39, p<0.001 ;$ unvowelized syntax $7 \%, \mathrm{~F}(2,28)=44.49, p$ $<0.001$, and both explained $77 \%$. When only the vowelized measures were entered as independent variables, again only vowelized word reading measure was a significant predictor and explained $70 \%$ of the variance, $\mathrm{F}(1,28)=62.39, p<0.001$. Further, when only the unvowelized measures were entered, the unvowelized syntax scores showed significant prediction, explaining $43 \%$ of the variance, $\mathrm{F}(1,28)=20.63, p<0.001$; and unvowelized pseudowords with real root explained an additional $13 \%$ of the variance, $\mathrm{F}(2,28)=16.66, p<0.001$. Both variables explained $56 \%$ of the total variance.

Chronological-age-matched group. The same stepwise regression procedures were also used among this group. The vowelized word reading measure showed a significant prediction, $63 \%, \mathrm{~F}(12,30)=49.42, p<0.01$ and reading comprehension explained an additional $5 \%$ of the variance, $\mathrm{F}(2,30)=30.28$, and both variables explained $68 \%$ of the total variance. Further, when only the vowelized measures were entered, only the vowelized isolated words explained $63 \%$ of the variance, $F(1,30)=$ $49.42, p<0.001$. However, when the unvowelized measures were entered, pseudowords with real roots showed a significant prediction and explained, $37 \%$ of the variance $F(1,30)=16.90$, 
$p<0.001$; reading vowels that do not fit the context explained an additional $10 \%, \mathrm{~F}(2,30)=12.23, p<0.001$, and both explained $47 \%$ of the total variance.

Summary of results. Among the dyslexic readers pseudoword reading with real roots was the consistent and best predictor of unvowelized isolated words in the three stepwise regression procedures. Other variables, working memory, vowelized isolated words, spelling, and syntax, showed less consistency and a very small significant prediction. However, among the young reading-level-matched group reading, the vowelized isolated words measure was the best and consistent predictor in the first two regression procedures and pseudoword reading with real roots was the best predictor when only unvowelized measures were entered. Likewise, in the chronological-age-matched group, the vowelized word reading measure showed significant and consistent predictions in the first two stepwise regression procedures. In the third regression procedure when only the unvowelized measures were entered, only pseudowords with real roots showed significant prediction. In other words, dyslexic readers seemed to rely more on roots in reading whereas both control groups relied mainly on phonology (vowelized words) if available and on roots when vowelization was not available.

\section{Discussion}

The main results of our study are: a) the performance of the dyslexic readers on the orthographic measures was better than their performance on the phonological decoding measures; $b$ ) all participants from all groups performed better on vowelized measures compared with unvowelized measures; c) dyslexic readers rely more on morphology whereas normal readers rely more on morphology only when the script is unvowelized.

The results of our study show significant differences between the dyslexic readers and their chronological-age-matched readers on all measures, except for the orthography. This result indicates that dyslexia in Arabic is similar to other alphabetical dyslexia in other alphabetical languages (Abu-Rabia, Share, \& Mansour, 2003; Prunet, Beland, \& Mimouni, 2000). However, significant differences were revealed between the dyslexic readers and the young reading-level-matched readers, with the younger readers performing better on vowelized and unvowelized phonology, unvowelized orthography, vowelized reading comprehension and unvowelized pseudowords with real roots. This result confirms that the orthographic lexicon of dyslexic readers is richer than their phonological lexicon and they tend to rely on visual-orthographic reading rather than reading mediated via phonology. As a result their decoding abilities are poor compared to the two regular groups (Abu-Rabia, Share, \& Mansour, 2003; Stanovich, 1991; Stanovich et al., 1997). Because our dyslexic participants were eight graders, they had been exposed to print more than the normal young readers, and because their reading strategy relied more on visual-morphological symbols of words and less on phonology, such a strategy equipped them with a rich orthographic lexicon as compared with their reading-level-matched group (Cunningham \& Stanovich, 1990; Stanovich \& West, 1989). This result follows similar results of Abu-Rabia and Siegel (2002): the bilingual dyslexic readers and the monolingual dyslexic readers showed similar or better orthographic results when compared with the regular bilingual and monolingual readers. Consistently, in our studies, the dyslexic reader relied on the visual-orthographic information in printed words (Abu-Rabia, 2001; Abu-Rabia \&
Taha, 2004, 2006; Abu-Rabia \& Siegel, 2002; Siegel, Share, \& Geva, 1995).

The second finding of our study shows that all groups, dyslexic and normal readers, performed better on vowelized measures as compared to unvowelized measures, except for morphology and syntax. This finding is important and characterizes the importance of short vowelization in reading in Arabic orthography as a Semitic language; "Shallow" if vowelized and "deep" if unvowelized. Even the normal grade 8 readers benefited from the short vowels in their reading on almost all measures. This finding is similar to the findings of previous studies conducted among different ages in Hebrew (Shimron \& Sivan, 1994; Shimron, 1993; Abu-Rabia, 2001) and in Arabic (AbuRabia, 1997, 1998, 2000, 2001, 2002, 2007). Short vowelization in Arabic makes the development of reading a "short vowelization-dependent process" where young, advanced and adult readers need to rely on short vowelization (phonology) for correct pronunciation. In such orthography where morphology is complex, and vowelization of final letters of words serves as a grammatical function, this function is governed by sentence context. Thus, phonology in Arabic is a sentence context-dependent process. Thus, as Arabic reading is a short vowelization-dependent process, all readers need it regardless of age and reading level. In other words, the reading process, due to the nature of the Arabic orthography, could be slower than in other alphabetic languages, and perhaps reaching the level of automaticity in reading aloud measures is far from a realistic expectation (Abu-Rabia, 2001; Ibrahim, Eviatar, \& Aharon-Peretz, 2002). In support of these findings, Abu-Rabia (2007) tested reading accuracy of highly skilled adult native Arabic teachers using morphologically complex words. The results showed that roots of words and short vowelization were essential factors for reading accuracy. It is important to note that information processing in Arabic orthography is cognitively demanding and as a result, the information processing in this type of orthography is slow. Ibrahim, Eviatar and Aharon-Peretz (2002) argued that the complexity of the Arabic orthography slows its processing; such a conclusion enhances the argument that the Arabic orthography may demands higher cognitive attention for word decoding than other orthographies.

The main effect of roots across all groups enhances the argument that Arabic readers rely on morphological entities in their reading. Roots of words are the key to initial lexical access, and phonology is retrieved later for accurate pronunciation. Shimron (1999) argues that in Hebrew, a Semitic language like Arabic, the orthographic knowledge of Hebrew is attributed to the morphology of the Semitic languages and that reading in Hebrew is assisted by syntactic clues and their connection to phonology. This assumption has largely been supported (BenDror, Bentin, \& Frost, 1995; Frost, 1995; Frost, Forster, \& Dutch, 1997; Ravid, 2001, 2002; Taouk \& Coltheart, 2003).

Our third finding indicates that the dyslexic readers tend to rely on roots and short vowelization in reading words whereas normal readers tend to rely on roots only if words are unvowelized. Dyslexic readers compensate (Stanovich, 1980) for their poor phonological decoding through reliance on their visualorthographic reading, namely, the root identification strategy. Further, the morphological lexicon of the normal readers is richer than the lexicon of the dyslexic and the young readers, which enables them to use morphology without short vowelization something that explains the differences between these normal readers and their normal young controls. In addition, 
poor morphological abilities usually are weakened even more as they join poor phonological abilities among poor readers (Feldman \& Fowler, 1995). A number of studies have suggested that the development of morphology and phonology in reading is a mutual and a parallel process (Carlisle, 1995; Shankweiler et al., 1995; Siegel \& Ryan, 1984).

Wysocki and Jenkins (1987) tested students in grades 4, 6 and 8 on their use of morphological knowledge and its relation to their understanding of new words. They found that grade 4 students were the poorest in using morphological knowledge in comparison with the older grades. They tended to define words according to their base-words regardless of affixes (Freyd \& Baron, 1982; Wysocki \& Jenkins, 1987; Windsor, 1994; Tyler \& Nagy, 1989; Carlisle, 1995; Carlisle \& Nomanbhoy, 1993).

In sum, the findings of our study enhance Abu-Rabia, Share and Mansour's (2003) results regarding phonology and morphology in Arabic and that short vowelization is helpful to the reading of normal and dyslexic readers. The morphology of Arabic is also essential in the reading of all readers. Based on these findings a few conclusions can be drawn for the learning and teaching of Arabic: a) teaching Arabic should be practiced through explicit phonological drilling and full vowelization; $b$ ) teaching of Arabic should also include explicit learning of the morphology of Arabic, starting with the key to lexical access, the root; and c) the phonology and morphology should be jointly taught in order to allow natural reading and spelling development.

\section{REFERENCES}

Abd El-Minem, F. M. (1987). Elm al-sarf. Jerusalem: Al-Taufik Press. Abu Rabia, S. (1995). Learning to read in Arabic: Reading, syntactic, orthographic and working memory skills in normally achieving and poor Arabic readers. Reading Psychology: An International Quarterly, 16, 351-394. doi:10.1080/0270271950160401

Abu Rabia, S. (1997) Reading in Arabic orthography: The effect of vowels and context on reading accuracy of poor and skilled native Arabic readers. Reading and Writing: An Interdisciplinary Journal, 9, 65-78. doi:10.1023/A:1007962408827

Abu Rabia, S. (1998). Reading Arabic texts: Effects of text type, reader type and vowelization. Reading and Writing: An Interdisciplinary Journal, 10, 106-119. doi:10.1023/A:1007906222227

Abu Rabia, S. (2000). Effects of exposure to literary Arabic in a diglossic situation. Reading and Writing: An Interdisciplinary Journal, 13, 147-157. doi:10.1023/A:1008133701024

Abu Rabia, S. (2001). The role of vowels in reading Semitic scripts: Data from Arabic and Hebrew. Reading and Writing: An Interdisciplinary Journal, 14, 39-59. doi:10.1023/A:1008147606320

Abu Rabia, S. (2002). Reading in a root-based-morphology language: The case of Arabic. Journal of Research in Reading, 25, 320-330. doi:10.1111/1467-9817.00177

Abu Rabia, S. (2007). The role of morphology and short vowelization functions in reading Arabic of regular and dyslexic readers in grades 3, 6, 9, and 12. Journal of Psycholinguistic Research, 36, 89-106. doi:10.1007/s10936-006-9035-6

Abu Rabia, S., \& Siegel, L. S. (1995). Different orthographies, different context effects: The effects of Arabic sentence context in skilled and poor readers. Reading Psychology: An International Quarterly, 16, 1-18. doi:10.1080/0270271950160101

Abu Rabia, S., Share, D., \& Mansour, S. M. (2003). Word recognition and basic cognitive processes among reading-disabled and normal readers of Arabic. Reading and Writing: An Interdisciplinary Journal, 16, 423-442. doi:10.1023/A:1024237415143

Abu Rabia, S., \& Taha, H. (2004). Reading and spelling error analysis of native Arabic dyslexic readers. Reading and Writing: An Interdisciplinary Journal, 17, 651-689. doi:10.1007/s11145-004-2657-x
Abu Rabia, S., \& Taha, H. (2006). Phonological errors predominate in Arabic spelling across grades 1 to 9. Journal of Psycholinguistic Research, 35, 167-188. doi:10.1007/s10936-005-9010-7

Abu-Rabia, S., \& Awwad, Y. (2004) Morphological structures in visual word recognition: Evidence from Arabic. Journal of Research in Reading, 27, 321-336. doi:10.1111/j.1467-9817.2004.00235.x

Abu-Rabia, S., \& Siegel, L. (2003). Reading skills in three orthographies: The case of trilingual Arabic-Hebrew-English-speaking Arabic children. Reading and Writing: An Interdisciplinary Journal, 16, 611-634. doi:10.1023/A:1025838029204

Abu-Rabia, S., \& Siegel, L. S. (2002). Reading, writing, orthographic, phonological, syntactic and memory skills of bilingual Arabic-English speaking Arab children. Journal of Psycholinguistic Research, 31, 661-678. doi:10.1023/A:1021221206119

Anastasi, A. (1988). Psychological testing (6th ed.). New York: Macmillan.

Arnbak, E., \& Elbro, C. (2002). The effects of morphological awareness training on the reading and spelling skills of young dyslexics. Scandinavian Journal of Educational Research, 45, 229-251.

Azzam, R. (1989). Orthography and reading of the Arabic language. In P. G. Aaron, \& R. M. Joshi (Eds.), Reading and writing disorders in different orthographic systems (pp. 203-218). Dordrecht: Kluwer Academic Publishers. doi:10.1007/978-94-009-1041-6 12

Baddeley, A., \& Hitch, G. (1974). Working memory. In G. A. Bower (Ed.), The psychology of learning and motivation (pp. 47-89). New York: Academic Press.

Barron, R. W. (1998). Proto-literate knowledge: Antecedents and influences on phonological awareness and literacy. In C. Hulme, \& R. M. Joshi (Eds.), Reading and spelling development and disorders (pp. 153-173). Mahwah: Lawrence Erlbaum Associates.

Beland, R., \& Mimouni, Z. (2001). Deep dyslexia in the two languages of an Arabic/French bilingual patient. Cognition, 82, 77-126. doi: 10.1016/S0010-0277(01)00148-2

Ben-Dror, I., Bentin, S., \& Frost, R. (1995). Semantic, phonologic and morphologic skills in reading-disabled and normal children: Evidence from perception and production of spoken Hebrew. Reading Research Quarterly, 30, 876-893. doi:10.2307/748202

Bentin, S., Deutsch, A., \& Liberman, I. (1990). Syntactic competence and reading ability in children. Journal of Experimental Child Psychology, 48, 147-172. doi:10.1016/0022-0965(90)90053-B

Bentin, S., \& Frost, R. (1995). Morphological factors in visual word identification in Hebrew. In L. B. Feldman (Ed.), Morphological aspects of language processing (pp. 271-292). Hillsdale, NJ: Lawrence Erlbaum Associates.

Bradley, L., \& Bryant, P. E. (1983). Categorizing sounds and learning to read: A causal connection. Nature, 301, 419-421. doi: $10.1038 / 301419 \mathrm{a} 0$

Boder, E. (1973). Developmental dyslexia: A diagnostic approach based on three typical reading-spelling patterns. Developmental Medicine and Child Neurology, 15, 663-687. doi:10.1111/j.1469-8749.1973.tb05180.x

Bosse, M. L., Valdois, S., \& Tainturier, M. J. (2003). Analogy without priming in early spelling development. Reading and Writing: An Interdisciplinary Journal, 16, 693-716. doi:10.1023/A:1025883815395

Brady, S., Mann, V., \& Schmidt, R. (1987). Errors in short term-memory for good and poor readers. Memory and Cognition, 15, 444-453. doi:10.3758/BF03197734

Bruck, M. (1988). The word recognition and spelling of dyslexic children. Reading Research Quarterly, 23, 51-69. doi:10.2307/747904

Bruck, M. (1990). Word recognition skills of adults with childhood diagnoses of dyslexia. Developmental Psychology, 26, 439-454. doi:10.1037/0012-1649.26.3.439

Bruck, M. (1998). Outcomes of adults with childhood histories of dyslexia. In C. Hulme, \& R. M. Joshi (Eds.,), Reading and spelling: Development and disorders (pp. 179-200). Mahwah, NJ: Lawrence Erlbaum Associates.

Bryant, P. E., Maclean, M., \& Bradley, L. (1990). Rhyme, language, and children's reading. Applied Psycholinguistics, 11, 237-252. 


\section{doi: $10.1017 / \mathrm{S} 0142716400008870$}

Bryant, P., Nunes, T., \& Bindman, M. (1998). Awareness of language in children who have reading difficulties: Historical comparisons in a longitudinal study. Journal of Child Psychology and Psychiatry, 39, 501-510. doi:10.1017/S0021963098002194

Carlisle, J. F. (1995). Morphological awareness and early reading achievement, In L. B. Feldman (Eds.), Morphological aspects of language processing (pp. 189-210). Hillsdale, NJ: Lawrence Erlbaum Associates.

Castle, A., \& Coltheart, M. (1993). Varieties of developmental dyslexia. Cognition, 47, 149-180. doi:10.1016/0010-0277(93)90003-E

Cermac, L. S. (1983). Information processing deficiencies in children with learning disabilities. Journal of Learning Disabilities, 16, 599605. doi: $10.1177 / 002221948301601008$

Crammond, J. (1992). Analyzing the basic cognitive developmental processes of children with specific types of learning disability. In R. Case (Ed.), The mind's staircase. Hillsdale, NJ: Erlbaum.

Critchley, M. (1970). The dyslexic child. London: Heinemann.

Cunningham, A. E., \& Stanovich, K. E. (1990). Assessing print exposure and orthographic processing skill in children: A quick measure of reading experience. Journal of Educational Psychology, 82, 733740. doi:10.1037/0022-0663.82.4.733

Cronbach, L. J. (1984). Essentials of psychological testing (4th ed.). New York: Harper \& Row.

Daneman, M., Carpenter, P. A., \& Just, M. A. (1982). Cognitive processes and reading skills. Advances in Reading language Research, 1, 83-124.

Datterman, D. (1982). Does "G" exist? Intelligence, 6, 99-108.

Deutsch, A., \& Bentin, S. (1996). Attention factors mediating syntactic deficiency in reading disabled children. Journal of Experimental Child Psychology, 63, 386-415. doi:10.1006/jecp.1996.0055

Edwards, J. D., Walley, A. C., \& Ball, K. K. (2004). Phonological, visual and temporal processing in adults with and without reading disability. Reading and Writing: An Interdisciplinary Journal, 16, 737758. doi:10.1023/A:1027357810003

Ehri, L. C., \& Wilce, L. S. (1983). Development of word identification speed in skilled and less skilled beginning readers. Journal of Educational Psychology, 75, 3-18. doi:10.1037/0022-0663.75.1.3

Elbro, C., \& Arnbak, E. (1996). The role of morpheme recognition and morphological awareness in dyslexia. Annals of Dyslexia, 46, 209240. doi:10.1007/BF02648177

Feldman, L. B., \& Bentin, S. H. (1994). Morphological analysis of disrupted morphemes: Evidence from Hebrew. The Quarterly Journal of Experimental Psychology, 47, 407-435. doi:10.1080/14640749408401118

Felton, R. H. (1998). The development of reading skills in poor readers: Educational implications. In C. Hulme, \& R. M. Joshi (Eds.), Reading and spelling: Development and_disorders (pp. 219-233). Mahwah, NJ: Lawrence Erlbaum Associates.

Fletcher, J. M. (1985). Memory for verbal and nonverbal stimuli in learning disability subgroups: Analysis by selective reminding. Journal of Experimental Child Psychology, 40, 244-259. doi:10.1016/0022-0965(85)90088-8

Fowler, A. E. (1988). Grammatical judgement and reading skills in grade 2. Annals of Dyslexia, 38, 73-94. doi:10.1007/BF02648249

Fowler, A. E., \& Liberman, I. Y. (1995). The role of phonology and orthography in morphological awareness. In L. B. Feldman (Ed.), Morphological aspects of language processing (pp. 157-188). Hillsdale, NJ: Lawrence Erlbaum Associates.

Frith, U. (1985). Beneath the surface of developmental dyslexia. In K. E. Patterson, J. C. Marashall, \& M. Coltheart (Eds.), Surface dyslexia. (pp. 301-330). London: Lawrence Erlbaum Associates.

Frost, R., \& Bentin, S. (1992). Reading consonants and guessing vowels: Visual word recognition in Hebrew orthography. In L. Katz, \& R. Frost (Eds.), Orthography, phonology, morphology, and meaning (pp. 27-44). Amsterdam: North Holland. doi:10.1016/S0166-4115(08)62787-9

Frost, R., Forster, K. J., \& Deutsch, A. (1997). What can we learn from the morphology of Hebrew? A masked priming investigation of morphological representation. Journal of Experimental Psychology: Learning, Memory and Cognition, 23, 829-856. doi:10.1037/0278-7393.23.4.829

Genard, N., Mousty, P., Content, A., Alegria, J., Leybaert, J., \& Morais, J. (1998). Methods to establish subtypes of developmental dyslexia. In P. Reitsma, \& L. Verhoeven (Eds.), Problems and interventions in literacy development (pp. 163-176). Dordrecht: Kluwer Academic Publishers.

Hamphreys, L. G. (1979). The construct of general intelligence. Intelligence, 3, 105-120. doi:10.1016/0160-2896(79)90009-6

Hakes, D. T. (1982). The development of metalinguistic abilities: What develops? In S. Kuczaj (Ed.), Language condition and culture (pp. 163-210). Hillsdale, NJ: Erlbaum.

Henry, M. K. (1989). Beyond phonics: Integrated decoding and spelling instruction based on word origin and structure. Annals of Dyslexia, 38, 258-275. doi:10.1007/BF02648260

Henry, M. K. (1993). Morphological structures: Latin and Greek roots and affixes as upper grade code strategies. Reading and Writing: An Interdisciplinary Journal, 5, 227-241. doi:10.1007/BF01027486

Hockett, C. F. (1958). A course of modern linguistics. New York: Macmillan.

Holligan, C., \& Johnston, R. S. (1988). The use of phonological information by good and poor readers in memory and reading tasks. Memory and Cognition, 16, 522-523. doi:10.3758/BF03197053

Ibrahim, R., Eviatar, Z., \& Aharon-Peretz, J. (2002). The characteristics of Arabic orthography slow its processing. Neuropsychology, 16, 115. doi:10.1037/0894-4105.16.3.322

Isa, F. (2000). Elm El-Sarf. Amman: Dar Elnashir.

Jorm, A. F., \& Share, D. (1983). Phonological reading and reading acquisition. Applied Psycholinguistics, 4, 103-147. doi:10.1017/S0142716400004380

Laudanna, A., Badecker, W., \& Carmazza, A. (1992). Processing inflectional and derivational morphology. Journal of Memory and Language, 31, 333-348. doi:10.1016/0749-596X(92)90017-R

Liberman, I. Y., Shankweiler, B., Fischer, F. W., \& Carter, B. (1974). Explicit syllable and phoneme segmentation in the young child. Journal of Experimental Child Psychology, 18, 201-212. doi:10.1016/0022-0965(74)90101-5

Leong, C. K. (1999). Phonological and morphological processing in adult students with learning/reading disabilities. Journal of Learning Disabilities, 32, 224-238. doi:10.1177/002221949903200304

Leong, C. K. (1989). Productive knowledge of derivational rules in poor readers. Annals of Dyslexia, 39, 94-115. doi:10.1007/BF02656903

Levin, I., Ravid, D., \& Rappaport, S. (1999). Developing morphological awareness and learning to write: A two-way street. In T. Nunes (Ed.), Learning to read: An integrated view from research and practice (pp. 77-104). Dordrecht: Kluwer Academic Publishers. doi:10.1007/978-94-011-4826-9 5 5

Levin, I., Ravid, D., \& Rappaport, S. (2001). Morphology and spelling among Hebrew-speaking children: From kindergarten to first grade. Journal of Child Language, 28, 741-772. doi:10.1017/S0305000901004834

Lovegrove, W. (1993). Do dyslexic have a visual deficit? In S. F. Wright, \& R. Groner (Eds.), Facets of dyslexia and its remediation (pp. 33-49). Amsterdam: Elsevier Science Publishers.

Lyster, S. A. H. (2002). The effects of morphological versus phonological awareness training in kindergarten on reading development. Reading and Writing: An Interdisciplinary Journal, 15, 261-294. doi:10.1023/A:1015272516220

Madkor, A. (1987). Language and current folklore. Cairo: Dar-Althkafa Publications.

Mahony, D., Singson, M., \& Mann, V. (2000). Reading ability and sensitivity to morphological relations. Reading and Writing: An Interdisciplinary Journal, 12, 191-218. doi:10.1023/A:1008136012492

Mattingly, I. G. (1984). Reading, linguistic awareness and language acquisition. In Downing, \& R. Valtin (Eds.), Linguistic awareness and learning to read (pp. 9-25). New York: Springer-Verlag.

Menyuk, P., Chesnick, M., Liebergott, J. W., Korngold, B., D’Agostino, R., \& Belanger, A. (1991). Predicting reading problems in at-risk children. Journal of Speech and Hearing Research, 34, 893-903.

Metsala, L. J., \& Brown, G. (1998). Normal and dyslexic reading development: The role of formal models. In C. Hulme \& R. M. Joshi 
(Eds.), Reading and spelling development and disorders (pp. 235261). Mahwah, NJ: Lawrence Erlbaum Associates.

Meyler, A. (1993). Developmental associations between verbal and visual short term memory and the acquisition of reading. M.A. Thesis, Haifa: University of Haifa.

Meyler, A., \& Briznitz, Z. (1998). Developmental associations between verbal and visual short-term memory and the acquisition of decoding skill. Reading and Writing: An Interdisciplinary Journal, 10, 519540. doi:10.1023/A:1007915517339

Morais, J., Mousty, P., \& Kolinsky, R. (1998). Why and how phoneme awareness helps learning to read. In C. Hulme, \& R. M. Joshi (Eds.), Reading \& spelling development and disorders (pp. 127-152). Mahwah, NJ: Lawrence Erlbaum Associates.

Muter, V. (1998). Phonological awareness: Its nature and its influence over early literacy development. In G. Hulme \& R. M. Joshi (Eds.), Reading and spelling development and disorders (pp. 113-125). Mahwah, NJ: Lawrence Erlbaum Associates.

Oakhill, J., Cain, K., \& Yuill, N. (1998). Individual differences in children's comprehension skill: Toward an integrated model. In C. Hulme, \& R. M. Joshi (Eds.), Reading and spelling development and disorders (pp. 343-367). Mahwah, NJ: Lawrence Erlbaum Associates.

Perfitti, C. A. (1985). Reading ability. New York: Oxford University Press.

Prunet, J., Beland, R., \& Idrisi, A. (2000). The mental representation of Semitic words. Linguistic Inquiry, 31, 609-648. doi:10.1162/002438900554497

Ravid, D. (2001). Learning to spell in Hebrew: Phonological and morphological factors. Reading and Writing: An Interdisciplinary Journal, 14, 459-485. doi:10.1023/A:1011192806656

Ravid, D., \& Malenky, A. (2001). Awareness of linear and nonlinear morphology in Hebrew. First Language, 21, 25-56. doi:10.1177/014272370102106102

Ravin, J., Ravin, J. C., \& Court, J. H. (1993). Manual for Raven's progressive matrices and vocabulary scales revised. Oxford: Oxford Psychologists Press.

Schiff, R. (2003). The effects of.morphology and word length on the reading of Hebrew nominals. Reading and Writing: An Interdisciplinary Journal, 16, 263-287. doi:10.1023/A:1023666419302

Schiff, R., \& Ravid, D. (2004). Vowel representation in written Hebrew: Phonological, orthographic and morphological contexts. Reading and Writing: An Interdisciplinary Journal, 17, 241-265. doi:10.1023/B:READ.0000017668.48386.90

Shankweiler, D., Cram, S., Katz, L., Fowler, A. E., Liberman, A. M., Brady, S. A., Thornton, R., Lundquist, E., Dreyer, L., Fletcher, J. M., Stuebing, K. K., Shaywitz, S. E., \& Shaywitz, B. A. (1995). Cognitive profiles of reading disabled children: Comparison of language skills in phonology, morphology and syntax. Psychological Science, 6, 149-156. doi:10.1111/j.1467-9280.1995.tb00324.x

Share, D. L. (1995). Phonological recoding and self-teaching. Cognition, 55, 151-218. doi:10.1016/0010-0277(94)00645-2

Share, D., \& Levin, I. (1999). Learning to read and write in Hebrew. In M. Harris, \& Hatano (Eds.), A cross linguistic perspective on learning to read (pp. 89-111). Cambridge: Cambridge University Press.

Shimron, J. (1999). The role of vowels signs in Hebrew: Beyond word recognition. Reading and Writing: An Interdisciplinary Journal, 11, 301-319.

Shimron, J., \& Sivan, T. (1994). Reading proficiency and orthography: Evidence from Hebrew and English. Language Learning, 44, 5-27.

Siegel, L. S. (1999). Issues in the definition and diagnosis of learning disabilities. Journal of Learning Disabilities, 32, 304-319.

Siegel, L. S., \& Ryan, E. B. (1984). Reading disability as a language disorder. RASE, 5, 28-33.

Siegel, L. S., \& Ryan, E. B. (1988). Development of grammaticalsensitivity, phonological and short-term memory skills in normally achieving and learning disabled children. Developmental Psychology, 24, 28-37. doi:10.1037/0012-1649.24.1.28
Siegel, L. S., Share, D., \& Geva, E. (1995). Evidence for superior orthographic skills in dyslexics. Psychological Science, 6, 250-256. doi:10.1111/j.1467-9280.1995.tb00601.x

Snowling, M. J., Goulandris, N., \& Defty, N. (1996). A longitudinal study of reading development in dyslexic children. Journal of Educational Psychology, 88, 653-669. doi:10.1037/0022-0663.88.4.653

Snowling, M., Nation, K., \& Muter, V. (1999). The role of semantic and phonological skills in learning to read: Implications for assessment and teaching. In T. Nunes (Ed.), Learning to read: An integrated view from research and practice (pp. 195-208). Dordrecht: Kluwer Academic Publishers.

Sprenger-Charolles, L., Cole, P., Lacert, P., \& Serniclaes, W. (2000). On subtypes of developmental dyslexia: Evidence from processing time and accuracy scores. Canadian Journal of Experimental Psychology, 54, 87-103. doi: 10.1037/h0087332

Stanovich, K. E. (1980). Toward an interactive-compensatory model of individual differences in the development of reading theory. Reading Research Quarterly, 16, 32-71. doi:10.2307/747348

Stanovich, K. E. (1988). Explaining the differences between the dyslexia and the garden variety poor reader: the phonological core variable difference model. Journal of Learning Disability, 21, 590-604. doi: $10.1177 / 002221948802101003$

Stanovich, K. E. (1991). Discrepancy definitions of reading disability: Has intelligence led us astray? Reading Research Quarterly, 26, 1923. doi: $10.2307 / 747729$

Stanovich, K. E., \& Siegel, L. S. (1994). The phenotypic performance profile of reading-disabled children: A regression-based test of the phonological-core variable-difference model. Journal of Educational Psychology, 86, 24-53. doi:10.1037/0022-0663.86.1.24

Stanovich, K. E., \& West, R. (1989). Exposure to print and orthographic processing. Reading Research Quarterly, 24, 402-429. doi: $10.2307 / 747605$

Stolz, A. J., \& Feldman, L. B. (1995). The role of orthographic and semantic transparency of the base morpheme in morphological processing. In L. B. Feldman (Ed.), Morphological aspects of language processing (pp. 109-129). Hillsdale, NJ: Lawrence Erlbaum Associates.

Taouk, M., \& Coltheart, M. (2004). The cognitive processes involved in learning to read in Arabic. Reading and Writing: An Interdisciplinary Journal, 17, 2757.

Thorndike, R. L. (1986). Stanford-Binet intelligence scale (4th ed.). Chicago, IL: Riverside Publishing Company.

Tyler, A., \& Nagy, W. (1990). Use of derivational morphology during reading. Cognition, 36, 17-34. doi:10.1016/0010-0277(90)90052-L

Vellutino, F. R. (1979). Dyslexia: Theory and research. Cambridge, MA: MIT Press.

Vellutino, F. R., \& Scanlon, D. M. (1987). Phonological coding, phonological awareness, and reading ability: Evidence from a longitudinal and experimental study. Merrill Palmer Quarterly, 33, 321-363.

Vogel, S. A. (1974). Syntactic abilities in normal and dyslexic children. Journal of Learning Disabilities, 7, 103-109. doi:10.1177/002221947400700211

Vogel, S. A. (1983). A qualitative analysis of morphologic development in learning disabled and achieving children. Journal of Learning Disabilities, 6, 457-465.

Webster, P. E. (1994). Linguistic factors in reading disability: A model for assessing children who are without overt language impairment. Child Language Teaching and Therapy, 10, 259-277. doi: $10.1177 / 026565909401000302$

Willows, D. M., \& Ryan, E. B. (1981). Differential utilization of syntactic and semantic information by skilled and less skilled readers in the intermediate grades. Journal of Educational Psychology, 73, $607-$ 615. doi: $10.1037 / 0022-0663.73 .5 .607$

Wydell, T. N., \& Butterworth, B. (1999). A case study of an EnglishJapanese bilingual with monolingual dyslexia. Cognition, 70, 273305. doi:10.1016/S0010-0277(99)00016-5 